\title{
PLANOS E POLÍTICAS URBANAS RELACIONADAS À MOBILIDADE ATIVA EM CURITIBA: \\ $O$ potencial pouco explorado do bairro Centro
}

\section{URBAN PLANS AND POLICIES RELATED TO ACTIVE MOBILITY IN CURITIBA: \\ The underexplored potential of the neighborhood Centro}

\author{
A. Bruno Marcos Kleis Jankowski \& B. Maria Carolina Maziviero \\ Universidade Federal do Paraná, Brasil \\ brunojankow@gmail.com \\ mcarolmazi@hotmail.com
}

\begin{abstract}
RESUMO
Este artigo foi elaborado a partir das pesquisas desenvolvidas para um Trabalho Final de Graduação apresentado como conclusão do Curso de Arquitetura e Urbanismo da Universidade Federal do Paraná e busca analisar planos e políticas urbanas do município de Curitiba que estejam relacionadas à mobilidade ativa. A metodologia adotada consiste no estudo de propostas e regulamentações urbanísticas, assim como no desenvolvimento de levantamentos morfológicos, de usos e de fluxos da área central da cidade. A partir do confronto entre as informações da análise e dos levantamentos será discutido o modo como tais propostas estão sendo desenvolvidas e como o bairro Centro está sendo abordado nelas. Como resultado, é discorrido sobre, se há um contexto favorável para a implantação de ações de incentivo ao uso de modais de transportes ativos, apontando quais características do bairro Centro poderiam ser melhor exploradas nas decisões de planos e projetos focados em mobilidade ativa.
\end{abstract}

Palavras-chave: planejamento urbano, mobilidade ativa, áreas centrais, Curitiba.

Linha de Investigação: 2 Cidade e Ambiente

Tópico: Acessibilidade e mobilidade sustentável

\section{ABSTRACT}

This article was made from the research developed for a final graduation work presented as the conclusion of the Architecture and Urbanism course at the Universidade Federal do Paraná and seeks to analyze urban plans and policies of the city of Curitiba which are related to active mobility. The research methodology adopted consists in the study of urban proposals and regulations, as well as the development of surveys about morphology, uses and flows of the central area of the city. From the confront between the information of the analysis and surveys it will be discussed the way in which this proposals are being developed and how the neighborhood Centro is being approached in them. As results, it is discoursed if a favorable context to realize urban actions to encourage the use of active modals of transport exists, indicating which characteristics of the 



\section{SÃOPAULO15 $17 \cdot$ LISBOA $25 \sim 26$ JUN 2020}

SIIUl.

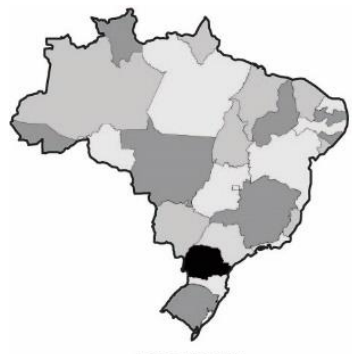

BRASIL

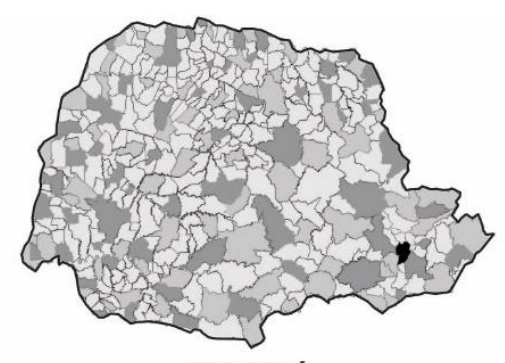

PARANÁ

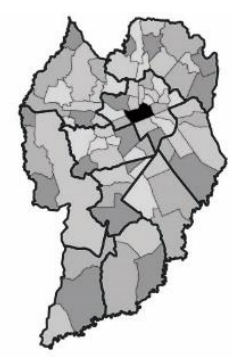

CURITIBA

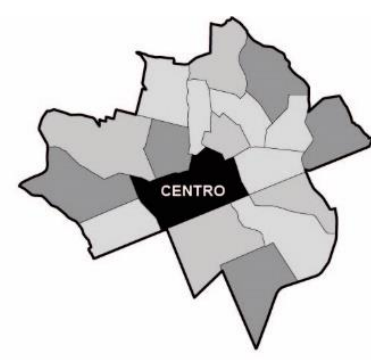

REGIONAL MATRIZ

Fig. 01 Diagrama de localização do bairro Centro: Elaboração própria (2020).

\section{Delimitação conceitual}

A temática da mobilidade ativa abrange diferentes conceitos, entre eles transporte ativo, transporte nãomotorizado, caminhabilidade e mobilidade urbana sustentável. Sendo assim, delimitá-los é essencial para uma compreensão clara do estudo desenvolvido neste artigo.

Enquanto o transporte ativo corresponde aos meios de transporte movidos exclusivamente à propulsão humana (Brasil, 2017), o transporte não-motorizado abrange os modais capazes de promover a circulação de pessoas e mercadorias sem necessitar do motor à combustão (ONU, 2017).

Já caminhabilidade, segundo Vargas e Netto (2017), é uma propriedade espacial que depende da articulação de fatores urbanos globais, locais e da morfologia arquitetônica. O primeiro envolve densidade, diversidade de usos e acessibilidade viária, o segundo abrange os aspectos físicos do ambiente de circulação do pedestre e o terceiro é o elemento que associa tais fatores e consolida as condições de caminhabilidade de um lugar.

Sinteticamente, mobilidade urbana sustentável refere-se à qualidade e eficiência das infraestruturas e meios de transporte na otimização do tempo e das distâncias dos deslocamentos cotidianos, sendo assim determinada pelo grau de acessibilidade que a cidade oferece aos seus moradores (ONU,2017). Além disso, Leite e Awad (2012) afirmam que ela é definida pelo incentivo ao uso de transportes não-motorizados em detrimento do uso do automóvel individual, associado ao investimento em um transporte coletivo integrado às questões de uso do solo e soluções inovadoras de gestão e monitoramento dos sistemas de transportes.

Embora fundamentais, tais termos não tratam especificamente do conceito de mobilidade ativa. Portanto, considerando que mobilidade urbana se refere às condições em que são realizados os deslocamentos de pessoas e cargas no espaço urbano (Brasil, 2012). Para a elaboração deste artigo, entende-se mobilidade ativa como a qualidade e eficiência em que as pessoas se deslocam no espaço urbano através da utilização de modais de transporte movidos à propulsão humana. Nesse caso, caracteriza-se qualidade e eficiência pela variação dos níveis de segurança, sustentabilidade, saúde e agilidade oferecidos pelas infraestruturas e pelos modais constituintes do sistema de mobilidade urbana (Jankowski, 2019).

\section{Planejamento e políticas urbanas municipais}

O planejamento urbano institucional de Curitiba, aquele em que a municipalidade passou a atuar como principal articuladora do processo, teve como marco inicial a elaboração do Plano de Urbanização de 1943, liderado pelo urbanista francês Alfred Agache. Duas décadas depois, o urbanista Jorge Wilheim e o recémcriado Instituto de Pesquisa e Planejamento Urbano de Curitiba contribuíram para o desenvolvimento do 


\section{SÃO PAULO15 $\sim 17 \cdot$ LISBOA $25 \sim 26$ JUN 2020

Plano Diretor de 1966 (Irazábal, 2018). Os desdobramentos desse plano tornaram Curitiba uma referência internacional de planejamento urbano, pois organizaram o modelo de desenvolvimento urbano através da delimitação de setores estruturais, compostos por um sistema trinário de vias integrado às questões de uso e ocupação do solo.

Já nas décadas de 1970 e 1980 a cidade se destacou nacionalmente por concretizar ações de incentivo aos modais ativos, como a abertura de ruas exclusivas para pedestres na área central (Irazábal, 2018) e a implantação de suas primeiras ciclovias, conectando parques da cidade (Belotto, 2014). Este pioneirismo fez de Curitiba o munícipio brasileiro com maior malha cicloviária até os anos 2000 (Patrício; Medeiros, 2015). Apesar do título, ela não se tornou um modelo, visto que ao se limitar a conectar parques, considerou a bicicleta somente como instrumento de lazer, desqualificando-a como meio de transporte (Belotto, 2014).

A compreensão desse contexto é essencial, pois até hoje o Plano de 1966 é a base do planejamento urbano de Curitiba. Isso se deve ao fato de que tanto a adequação ao Estatuto da Cidade (2001), realizada em 2004 através da Lei Municipal № 11.266/2004, quanto a revisão, elaborada em 2015 por meio da Lei Municipal № 14.771/2015, dizem respeito a ele (Curitiba, 2015).

Entre as partes integrantes do atual plano diretor estão os planos setoriais e os estratégicos, assim como as políticas urbanas e de uso do solo. Considerando isso, este artigo terá foco na análise das políticas urbanas relacionadas à mobilidade ativa do Plano Setorial de Mobilidade e Transporte Urbano Integrado (2008), do Plano Estratégico Cicloviário (2013) e do Plano Estratégico de Pedestrianização e Calçadas (2014).

Todavia, vale pontuar que esses três planos foram elaborados antes da aprovação da Lei Municipal № $14.771 / 2015$, estando desatualizados em relação ao plano diretor vigente.

\subsection{Políticas urbanas}

A Lei Municipal № 14.771/2015 dispõe sobre a revisão do Plano Diretor de Curitiba. Ele é considerado o instrumento básico da política de desenvolvimento urbano da cidade e em diversos trechos aborda questões diretamente relacionadas à temática da mobilidade ativa.

As diretrizes da política de estruturação urbana são um exemplo. Sucintamente, elas visam promover um crescimento urbano integrado ao uso do solo e às infraestruturas de transporte, que contribua para integrar diferentes usos, edificações e formas de ocupação territorial, assim como para requalificar o centro da cidade.

O reflexo dessas diretrizes no macrozoneamento proposto fica evidente ao serem delimitados eixos estruturantes de crescimento e áreas de ocupação mista com o objetivo de promover a mistura de usos de acordo com as características e a infraestrutura de cada região (Curitiba, 2015). Os eixos estruturantes seguem as ideias do plano de 1966, definindo o modelo de expansão do centro tradicional através de incentivos à diversidade de usos, às altas densidades e ao uso do transporte coletivo. Já as áreas de ocupação mista são caracterizadas como de alta, média e baixa densidade de ocupação, estando a mais importante delas localizada em parte dos bairros Centro, São Francisco e Centro Cívico (fig. 02).

Tais caraterísticas do macrozoneamento e as diretrizes de estruturação urbana que o norteiam são fundamentais para promover a mobilidade ativa. Afirma-se isso com base nos ideais de Jacobs $(2011)^{1}$, Gehl

${ }^{1}$ Título original: The dead and life of great American cities (1961). 


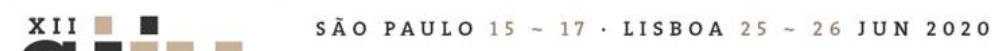

Seminário Internacional de Investigação em Urbanismo

$(2015)^{2}$ e Speck (2017) ${ }^{3}$. Eles argumentam que alta densidade, diversidade de usos e um sólido sistema de transporte público são condições essenciais para atrair as pessoas a caminhar e pedalar pelas ruas.

Outro fator importante para a vitalidade urbana, e consequentemente para a mobilidade ativa, desenvolvido por Jacobs (2011) e Gehl (2015), são as fachadas ativas. Elas são definidas no plano como fachadas de uso não-residencial, com abertura voltada para o espaço público e no nível da calçada, cujo objetivo é estimular a mistura e reduzir o deslocamento entre usos (Curitiba, 2015). O plano indica ainda os eixos estruturantes, as áreas de ocupação mista e as centralidades como prioridades para a elaboração de estudos sobre incentivos à construção de fachadas ativas.

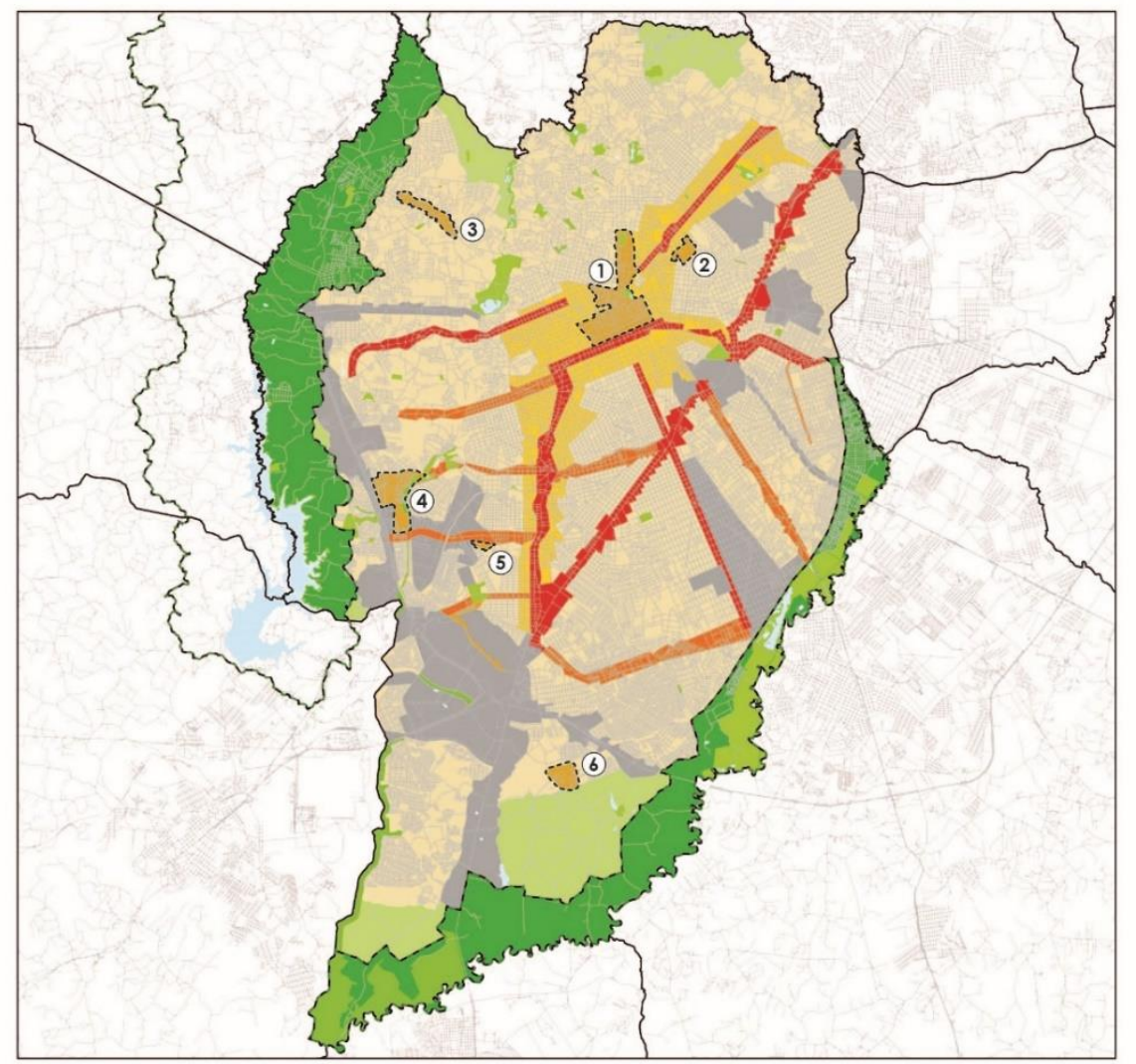

MACROZONEAMENTO E

DENSIDADE DE OCUPAÇÃO

\section{LEGENDA}

EIXO ESTRUTURANTE

- eixo de ADensamento

AREA COM PREDOMINANNCIARESIDENCIAL
OE MEDEAODENSIDODE

AREACOM PREDAOIINÁNCIA RESIDENCIAL
DE BAIXA DENSIDADE

2.: AREA DE OCUPAÇ̄OM MISTA

AREA COM DESTINAÇ̄o ESPECIFICA

- área de ocupaçäo Controlada

- AREADE PROTEÇÃO AMBIENTAL

UNIDADE DE CONSERVAÇĀO

$\square$ LIMITE DAÁREA DE PROTEÇÃO AMBIIENTAL

DIVISAS MuniliPaIS

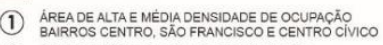

(2) AREADE MEDEA DENSIDADE DE OCUPACGAO

(3) AREADE BAXAXDENSIDADE DE OCUPAÇ̄̃

(4) AREAD MEDALDENSIDADE DE OCUPACĀO
BAIRRO CIDAOE INOUSTRIAL DE CURITIBA

(5) AREA DE MEDIADENSIDADE DE OCUPACÃO
BAIRROS CIDADE INDUSTRIALL DE CURTIIAA

(6) AREADE BAIXADENSIDADE DE OCUPAÇÃO

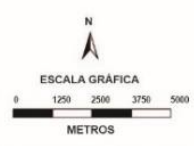

PLANO DIRETOR DE CURITIBA

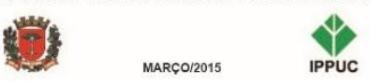

Fig. 02 Proposta de Macrozoneamento do Plano Diretor de Curitiba: Modificado de Curitiba (2015).

As diretrizes para a mobilidade urbana detalhadas no plano também valorizam a mobilidade ativa. Sinteticamente, elas defendem a promoção de políticas públicas que reduzam o uso de modais motorizados e individuais, favorecendo a ampliação dos coletivos e não motorizados na divisão modal, através de um sistema de transporte com infraestrutura segura, integrada e que priorize os pedestres (Curitiba, 2015).

Para viabilizá-las são definidos instrumentos como: a) expandir e consolidar áreas exclusivas para transporte coletivo e não motorizado; b) universalizar e integrar o sistema de transporte coletivo; c) viabilizar o bilhete único integrado aos estacionamentos intermodais; d) incentivar o uso de modais não motorizados e coletivos, através de medidas de acalmamento de tráfego e compartilhamento do espaço público (Curitiba, 2015).

2 Título original: Cities for people (2010).

${ }^{3}$ Título original: Walkable City: How downtown can save America, one step at a time (2010). 


\section{SÃO PAULO15 17 LISBOA $25 \sim 26$ JUN 2020

Ainda sobre a circulação não motorizada, o plano defende a acessibilidade e a equidade no uso do espaço público de circulação, a implantação de um sistema de bicicletas compartilhadas integradas ao transporte coletivo e o desenvolvimento de um plano cicloviário. O detalhamento dessas diretrizes não aparece no plano, mas sim em legislações complementares que serão analisadas a seguir.

A Lei Municipal № 11.095/2004 estabelece o código de posturas do munícipio. Dentre as suas regulamentações, a que mais impacta o cotidiano dos pedestres trata da responsabilidade pela manutenção das calçadas. Segundo o código, a construção e manutenção dos passeios na testada do lote compete aos proprietários, que devem seguir os padrões especificados no Decreto Municipal № 1.066/2006 (Curitiba, 2004).

Apesar dessas normatizações, o Decreto Municipal № 988/2004 determina que a construção de passeio só é obrigatória nas vias providas de meio-fio, sendo que esses, de acordo com o Decreto 1.066/2006, só podem ser implantados em vias dotadas de pavimentação definitiva. Tal regulamentação é prejudicial à continuidade e homogeneidade dos passeios e compromete a eficácia das demais normativas municipais relacionadas.

A Lei Municipal № 11.596/2005 também aborda a questão das calçadas ao estabelecer a criação do Fundo de Recuperação de Calçadas (FUNRECAL) e o Programa Caminhos da Cidade. Segundo ela, as multas relativas às calçadas integram as receitas do fundo, que destina a verba ao programa, visando viabilizar intervenções de requalificação de calçadas, através de parcerias com a iniciativa privada e a sociedade (Curitiba, 2005).

A criação do FUNRECAL e do Programa Caminhos da Cidade são decisões questionáveis, pois a municipalidade encarrega o proprietário da construção do passeio e paralelamente cria um fundo cujo objetivo é recuperar as calçadas. Tais instrumentos seriam interessantes caso o município se responsabilizasse pelos passeios, porém, do modo como estão, apenas aumentam a complexidade dessa questão.

Critica-se ainda a ausência de fiscalização adequada, visto que ao caminhar pelas ruas é nítida a predominante inadequação dos passeios em relação aos padrões estabelecidos. Os resultados disso são condições precárias de deslocamento para os pedestres, que pouco se sentem atraídos a caminhar, e a ineficiência do FUNRECAL, visto que os recursos das multas que deveriam ser aplicadas deixam de ser arrecadados.

\subsection{Plano de Mobilidade e Transporte Urbano Integrado - PlanMob (2008)}

O Plano de Mobilidade e Transporte Urbano Integrado de Curitiba, ou PlanMob, é um dos planos setoriais previstos no Plano Diretor aprovado em 2004 que permaneceu como parte integrante do plano revisado em 2015. Ele foi finalizado em 2008, e por ser um plano setorial, sua elaboração buscou materializar os princípios, os objetivos e as diretrizes referentes à mobilidade, previstos no Plano Diretor (Curitiba, 2015).

Para atingir o objetivo de definir políticas, diretrizes e ações para o cenário metropolitano da cidade em 2020 , abordaram-se quatro temas: 1) acessibilidade; 2) circulação e sistema viário; 3) sistemas de transporte coletivo e comercial; 4) sistema de transporte de cargas. Cada tema foi dividido em subtemas e diretrizes de atuação. Os objetivos de cada tema tangenciam a problemática da mobilidade ativa. Os dois últimos abordam de maneira indireta, enquanto o segundo defende explicitamente uma mobilidade menos agressiva à vida e ao meio ambiente, que priorize o uso de modais ativos e coletivos. 


\section{SÃO PAULO15 $17 \cdot$ LISBOA $25 \sim 26$ JUN 2020}

Referente ao tema da acessibilidade, todos os subtemas abordam diretrizes ligadas à mobilidade ativa. As principais propostas são a adequação das leis relacionadas à manutenção dos passeios, a definição de rotas acessíveis e a melhoria das condições de acessibilidade no transporte coletivo e em equipamentos urbanos.

Já o tema sistema viário, de circulação e de trânsito foi dividido em quinze subtemas. Três deles abordam questões sobre a mobilidade ativa: a) classificação, tipologia, e hierarquização do sistema viário; b) utilização do sistema viário básico; e c) componentes do Sistema de Trânsito. Resumidamente, é defendida a ampliação de infraestruturas voltadas aos usuários de modais ativos e coletivos, aliada a uma reestruturação urbana que priorize a circulação não motorizada na área central e que desenvolva conexões cicloviárias metropolitanas.

Considerando essa síntese focada no contexto da mobilidade ativa, constata-se que, apesar de apresentar diagnóstico e diretrizes bem definidas, o PlanMob não define intervenções concretas ou estratégias capazes de alterar as condições da mobilidade urbana de Curitiba. Tal fato reflete-se nos planos que serão analisados a seguir, que mesmo apresentando propostas têm dificuldade em abordar a mobilidade de maneira integrada.

\subsection{Plano Cicloviário - PlanCiclo (2013)}

O PlanCiclo (2013) foi elaborado com o objetivo principal de implantar $300 \mathrm{~km}$ de vias cicláveis pela cidade, podendo elas serem constituídas por ciclorrotas, vias calmas, ciclovias, ciclofaixas e passeios compartilhados (fig. 03) (IPPUC, 2013). Por ser um plano estratégico, seu conteúdo contempla um tema específico, mas que abrange todo o território (Curitiba, 2015).

\section{Plano Estratégico Cicloviário de Curitiba}

Marco de humanização do espaços públicos.

Investimento de mais de $\mathrm{R} \$ 90$ milhões.

\section{A Bicicleta como um modal de transporte \\ $300 \mathrm{~km}$ de vias cicláveis: \\ - $90 \mathrm{~km}$ de ciclorotas \\ - $80 \mathrm{~km}$ de vias calmas \\ - 130 km de vias cicláveis (entre ciclovi ciclofaixas e passeios compartilhados entre pedestres e ciclistas)}
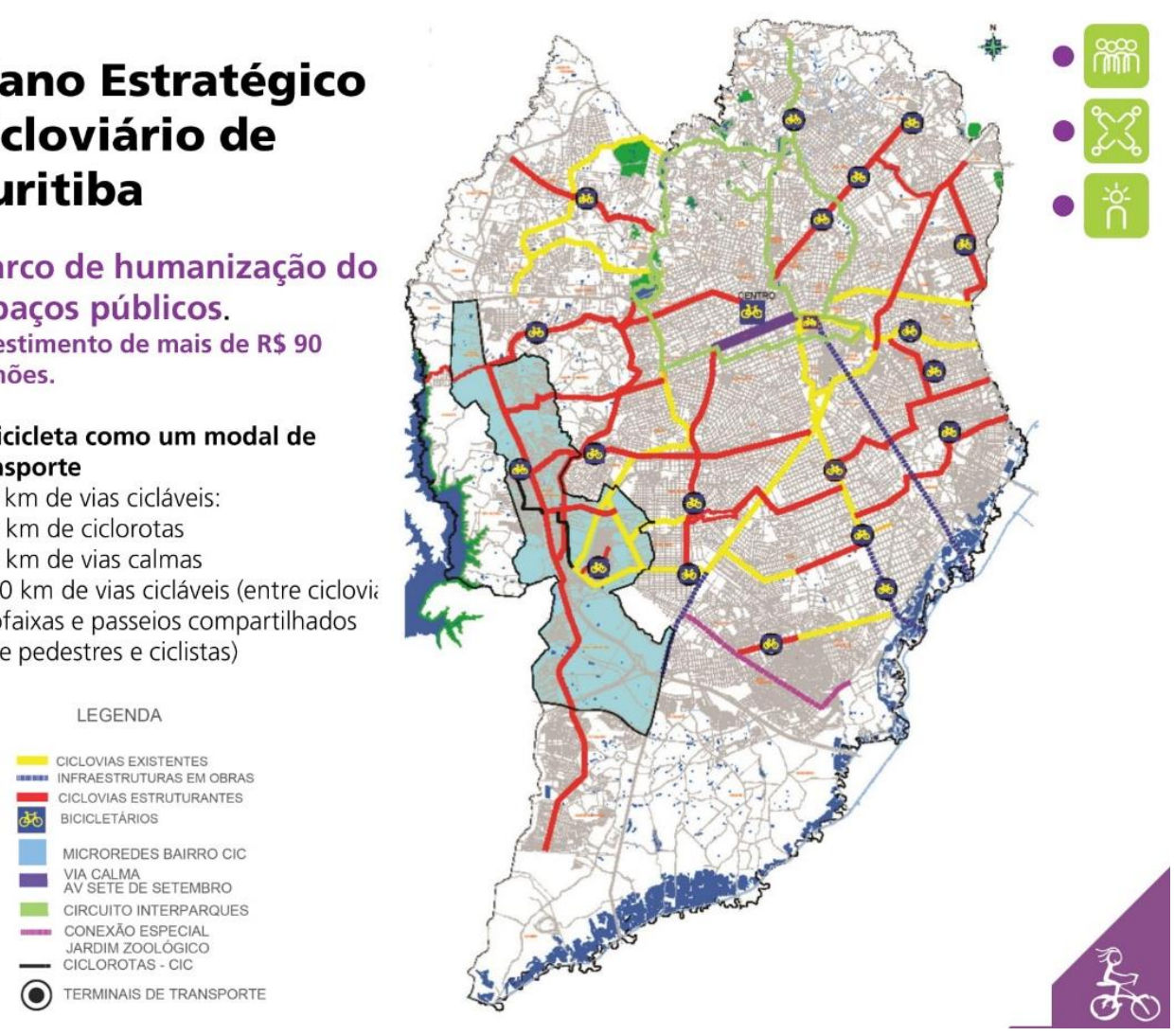


\section{SÃO PAULO15 $\sim 17 \cdot$ LISBOA $25 \sim 26$ JUN 2020

Fig. 03 Mapa dos 300 km de vias cicláveis propostas: IPPUC (2013)

Para atingir tal objetivo, são detalhadas seis propostas: 1) a criação de uma microrrede cicloviária no bairro Cidade Industrial de Curitiba; 2) a implantação de via calma com 6,3 km de extensão na Avenida Sete de Setembro; 3) a requalificação de 2,65 km da estrutura viária da Avenida Manoel Ribas; 4) a conclusão do Circuito Interparques, totalizando $47 \mathrm{~km}$; 5) a implantação de paraciclos e bicicletários, principalmente na área central e próximo aos terminais; 6) a elaboração da Praça de Bolso do Ciclista no bairro Centro de Curitiba.

Diferentemente do PlanMob (2008), o Plano Cicloviário de Curitiba (2013) detalha melhor suas propostas, definindo locais, prazos, infraestrutura e custos das ações. Além disso, atua em diferentes áreas da cidade e considera a infraestrutura já existente. Das estratégias, destacam-se a da microrrede cicloviária, a da implantação de vias calmas e a da instalação de paraciclos e bicicletários. Esta última aponta os locais em que eles serão implantados, a disposição adequada em relação à via e os seus detalhes construtivos.

Ressalta-se ainda que as propostas de implantação da via calma na Avenida Sete de Setembro, dos paraciclos e da Praça de Bolso do Ciclista, assim como a requalificação da Avenida Manoel Ribas, foram realizadas e impactaram positivamente nas condições de deslocamentos dos ciclistas no entorno imediato da intervenção.

Outro aspecto positivo é o fato de que o plano foi feito em parceria com uma associação de ciclistas da cidade, a Ciclolguaçu. Ela colaborou participando de seminários, consultas públicas e pesquisas junto aos ciclistas, com o intuito de avaliar as principais necessidades e aproximar o plano da realidade local (IPPUC, 2013).

Todavia, mesmo efetivando algumas de suas propostas e contando com a participação ativa de ciclistas, o PlanCiclo é passível de críticas, pois não conseguiu alterar o fato de mais da metade da malha cicloviária de Curitiba ser composta por passeios compartilhados, ou seja, ocorrendo sobre as calçadas e competindo por espaço com os pedestres. Além disso, não aproveitou o potencial dos eixos estruturais como disseminadores de infraestrutura cicloviária pela cidade e pouco alterou o fato das ciclovias e ciclofaixas curitibanas atenderem mais a questão do lazer do que a das tarefas cotidianas da população (Belotto, 2014). Por fim, pode-se dizer que as ações concretizadas, apesar de pontuais, melhoraram as condições de mobilidade por bicicleta, comprovando a importância de se prover infraestrutura adequada aos modais de transporte ativos.

\subsection{Plano de Pedestrianização e Calçadas - PlanCal (2014)}

A descrição do PlanCal coloca-o como integrante de um Plano de Multimodalidade de Curitiba, que envolve o Plano Cicloviário, de lluminação, de drenagem e de prevenção de desastres naturais (IPPUC, 2014). Porém, como será abordado a seguir, suas estratégias voltam-se quase que exclusivamente à qualidade física das calçadas, não deixando clara a integração proposta.

Também denominado Plano Estratégico de Calçadas, o PlanCal (2014) pode ser dividido em cinco estratégias de atuação, são elas: 1) requalificar as calçadas, incluindo as de interesse histórico; 2) melhorar as condições de acessibilidade dos passeios e vias; 3) promover espaços urbanos mais seguros; 4) propor novos padrões de calçadas para imóveis em processo de regularização fundiária; 5) revisar a legislação referente às calçadas.

A primeira estratégia propõe a revitalização e implantação de $234 \mathrm{~km}$ de calçadas espalhadas pela cidade, mas com foco principal na área central, incluindo a reforma gradativa dos passeios em vias com valor cultural e com previsão de intervenção na infraestrutura cicloviária (fig.04). 


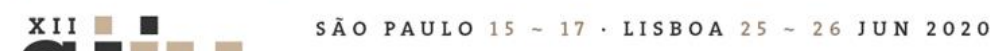

Seminário Internacional de Investigação em Urbanismo

Seminario Internacional de Investigación en Urbanismo

Já a segunda estratégia pretende assegurar a acessibilidade das calçadas e vias, através da reutilização da matéria-prima já existente nelas, do desenho contínuo e sem obstáculos dos passeios e da utilização de novas tecnologias para melhorar a visibilidade das faixas de pedestres.

A estratégia de promover espaços mais seguros é composta por duas propostas, a dos caminhos de luz e a das rotas seguras até as escolas. Ambas objetivam a melhoria das condições de segurança durante o deslocamento, por meio da implantação de rotas iluminadas conectando equipamentos públicos, vias importantes e estações de transporte público.

A quarta estratégia consiste em possibilitar novos padrões de calçadas para facilitar o processo de regularização fundiária pela cidade. O plano aponta as áreas em que será aplicado esse instrumento, porém não determina como seria esse novo modelo proposto. Por fim, a quinta proposta prevê a reformulação dos decretos das calçadas, com o intuito de disseminar calçadas executadas com melhor qualidade pela cidade.

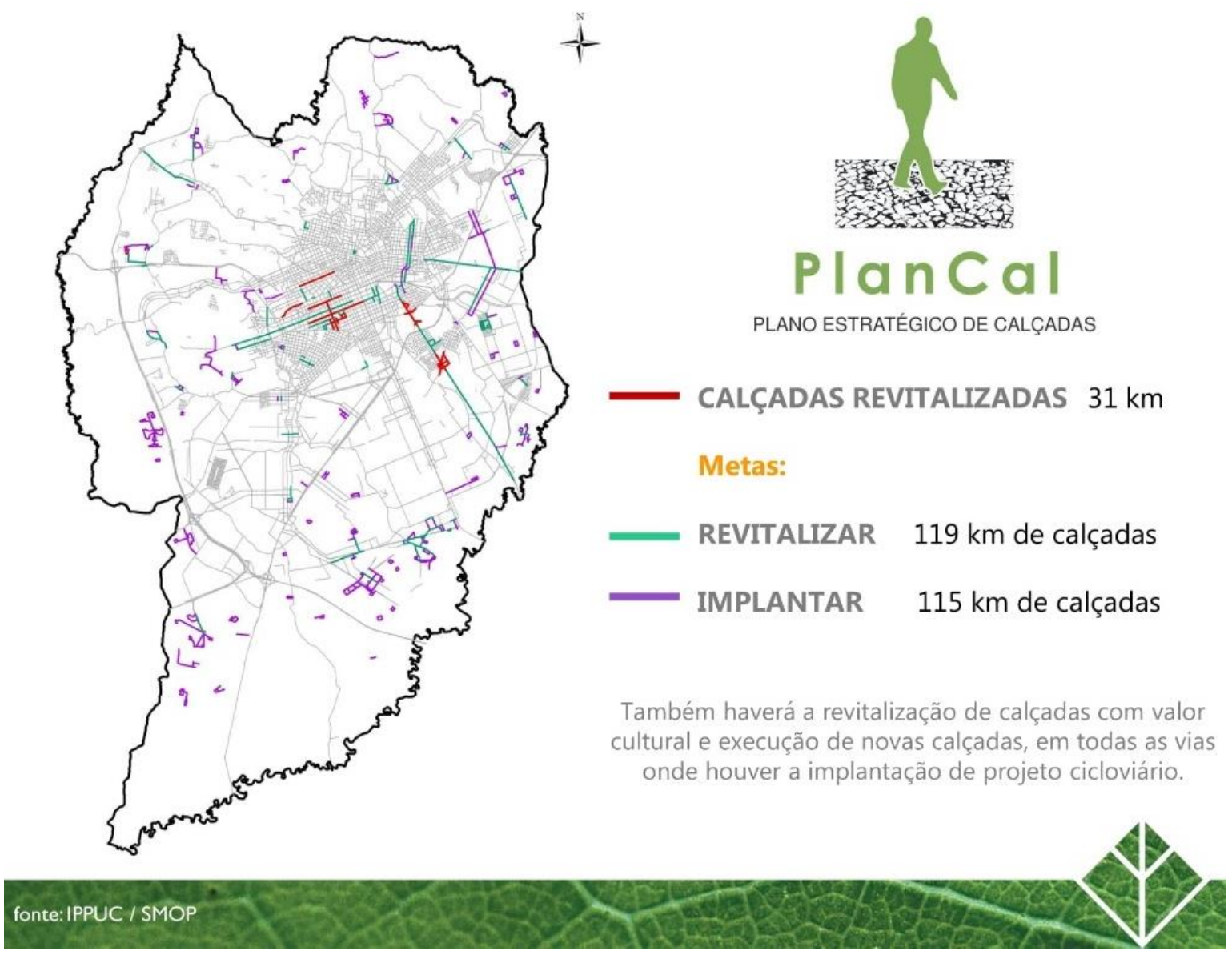

Fig. 04 Proposta de calçadas a serem revitalizadas pelo PlanCal: IPPUC (2014).

Diferentemente do PlanMob, o PlanCal faz proposições concretas para efetivar suas estratégias, porém, não detalha prazos e etapas como o PlanCiclo. Mesmo sendo mais consistentes, tais ações são dispersas e não integradas. Além disso, assim como as leis analisadas, o plano contradiz o fato de o proprietário do lote ser responsável pela calçada, pois encarrega o município pelas ações propostas. 


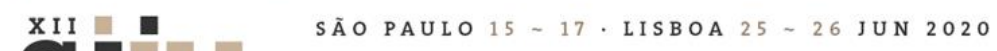

\section{西要}

Das estratégias detalhadas, poucas foram efetivadas. As duas primeiras provavelmente foram parcialmente aplicadas, porém não há como se precisar, devido à seleção dispersa que foi feita. Já as três últimas estratégias não surtiram efeito e tais problemas permanecem prejudicando as condições de mobilidade no município.

\section{Levantamento do bairro Centro}

A análise demonstrou que, além de desatualizados em relação ao Plano Diretor, os planos em questão pouco abordam a mobilidade ativa na área central, evidenciando uma realidade distante da proposta na Lei Municipal № 14.771/2015. Partindo disso, será analisado o contexto do bairro Centro e seu entorno a partir de três aspectos essenciais para a mobilidade ativa: a morfologia urbana, o uso do solo e os fluxos. A intenção é verificar se o cenário existente favorece a realização de intervenções urbanas voltadas à mobilidade ativa.

\subsection{Metodologia de levantamento}

A metodologia adotada variou de acordo com a característica dos dados necessários para avaliar cada aspecto, sendo que os dados foram coletados e sintetizados entre agosto e outubro de 2019.

Referente ao aspecto morfológico, a classificação dos tamanhos de quadras foi feita a partir da análise do mapa de arruamento de Curitiba, disponibilizado pela municipalidade em formato digital shapefile. Já para os dados de uso do solo, foram consultadas imagens disponíveis no Google Street View. Por fim, o levantamento de fluxos foi feito em 102 esquinas da área central de Curitiba, em diferentes horários e dias da semana, através da utilização de contador manual e cronômetro. O recorte de tempo computado foi de 60 segundos e o horário de levantamento variou entre 12 horas e 18 horas da tarde.

Visando minimizar possíveis imprecisões ou desatualizações, principalmente das informações sobre uso do solo, foram realizadas visitas de campo.

\subsection{Morfologia}




\section{SÃOPAULO15 17 LISBOA $25 \sim 26$ JUN 2020 \\ Seminário Internacional de \\ Seminario Internacional de Investigação em Urbanismo Investigación en Urbanismo}

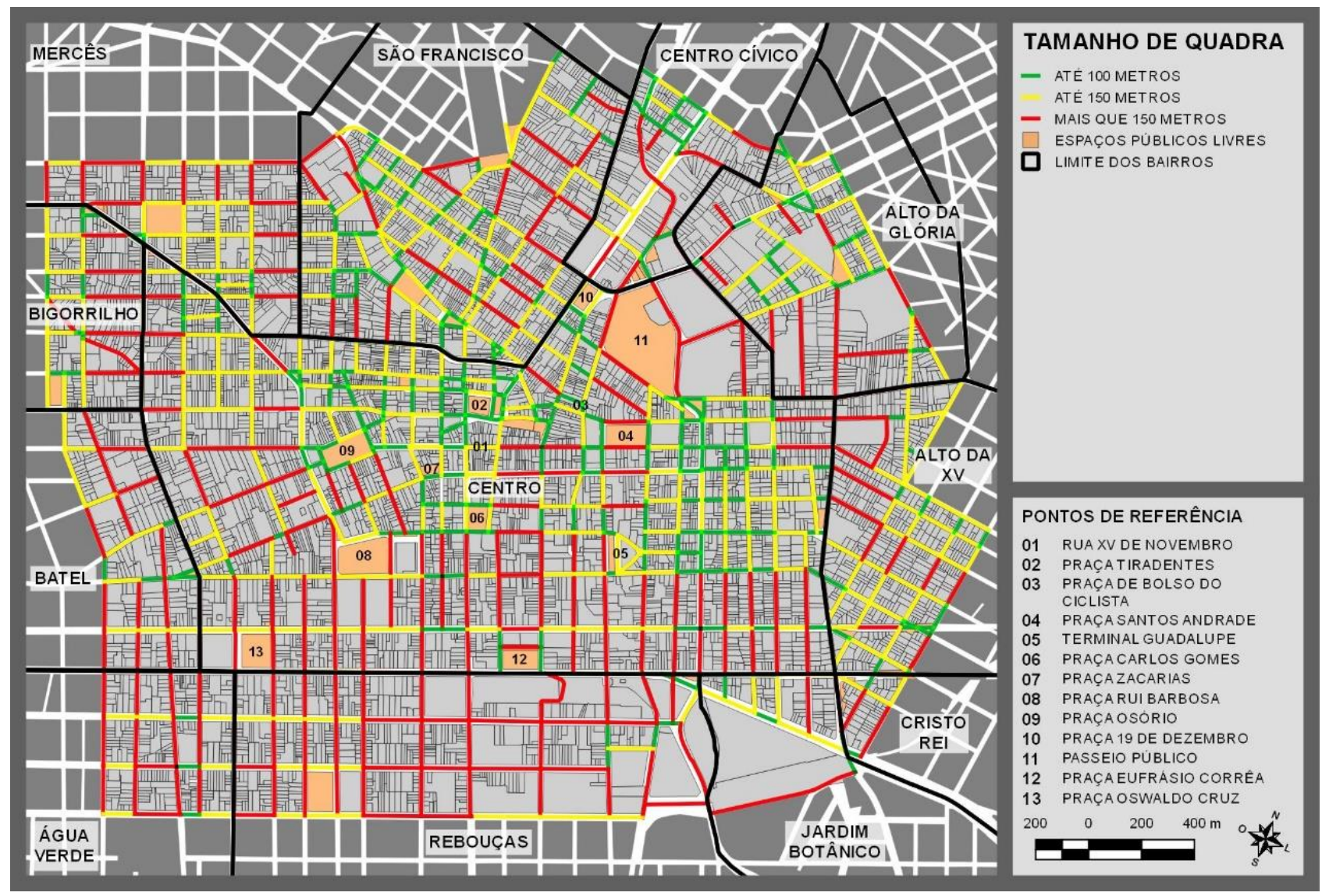

Fig. 05 Levantamento dos tamanhos de quadra no bairro centro e seus arredores: Elaboração própria (2020).

Através do levantamento dos tamanhos de quadra da área central de Curitiba, observa-se que a maior concentração de quadras curtas, com comprimento de até 100 metros, encontra-se no bairro Centro (fig.05). Esta informação é relevante pois quanto menor a distância entre quadras, mais encontros acontecem entre as pessoas e mais alternativas de rotas são passíveis de serem percorridas, o que acaba contribuindo para as condições de deslocamento dos usuários de modais ativos. Constata-se também que no restante da área predominam quadras mais longas, acima de 150 metros, principalmente ao sul, em direção ao bairro Rebouças, o que acaba atuando como uma barreira para a continuidade do tecido viário mais compacto.

\subsection{Usos}




\section{SÃO PAULO15 17 LISBOA $25 \sim 26$ JUN 2020 \\ Seminário Internacional de Seminario Internacional de Investigação em Urbanismo Investigación en Urbanismo}

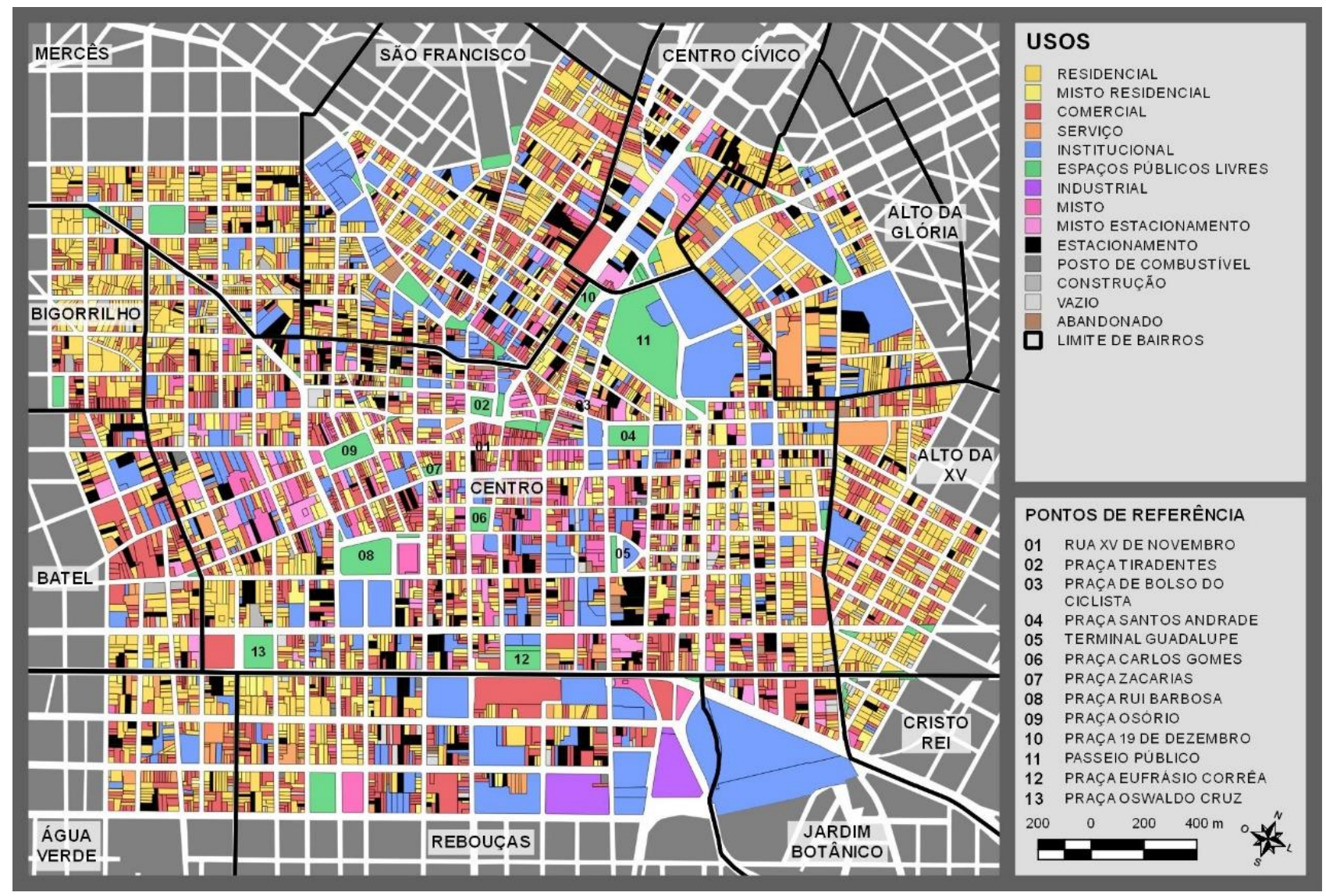

Fig. 06 Levantamento dos usos por lote no bairro centro e seus arredores: Elaboração própria (2020).

Já em relação aos usos existentes, observa-se que a área com predominância de uso misto se distribui através de três eixos que partem do núcleo central do bairro Centro, sendo um ao norte, outro ao sudoeste e o terceiro ao leste (fig.06). Nesses eixos ainda se encontram a maioria dos espaços públicos livres da região. A combinação entre usos mistos e espaços públicos é uma caraterística interessante para a mobilidade ativa, visto que reduz a distância entre funções e aumenta o fluxo e a permanência de pessoas nos espaços públicos livres.

Vale pontuar também que os lotes que se encontram fora desses três eixos são em sua maioria ocupados por edificações residenciais, exceto em áreas dos bairros São Francisco e Rebouças, que concentram lotes e edificações de uso institucional. Por fim, destaca-se negativamente o grande número de estacionamentos na área, pois eles geralmente contribuem pouco para a vitalidade das ruas, além de serem mais um incentivo para utilização de automóveis privados em uma área dotada de infraestrutura de transporte público consolidada.

\subsection{Fluxos}




\section{SÃOPAULO15 17 LISBOA $25 \sim 26$ JUN 2020 \\ Seminário Internacional de Seminario Internacional de Investigação em Urbanismo Investigación en Urbanismo}

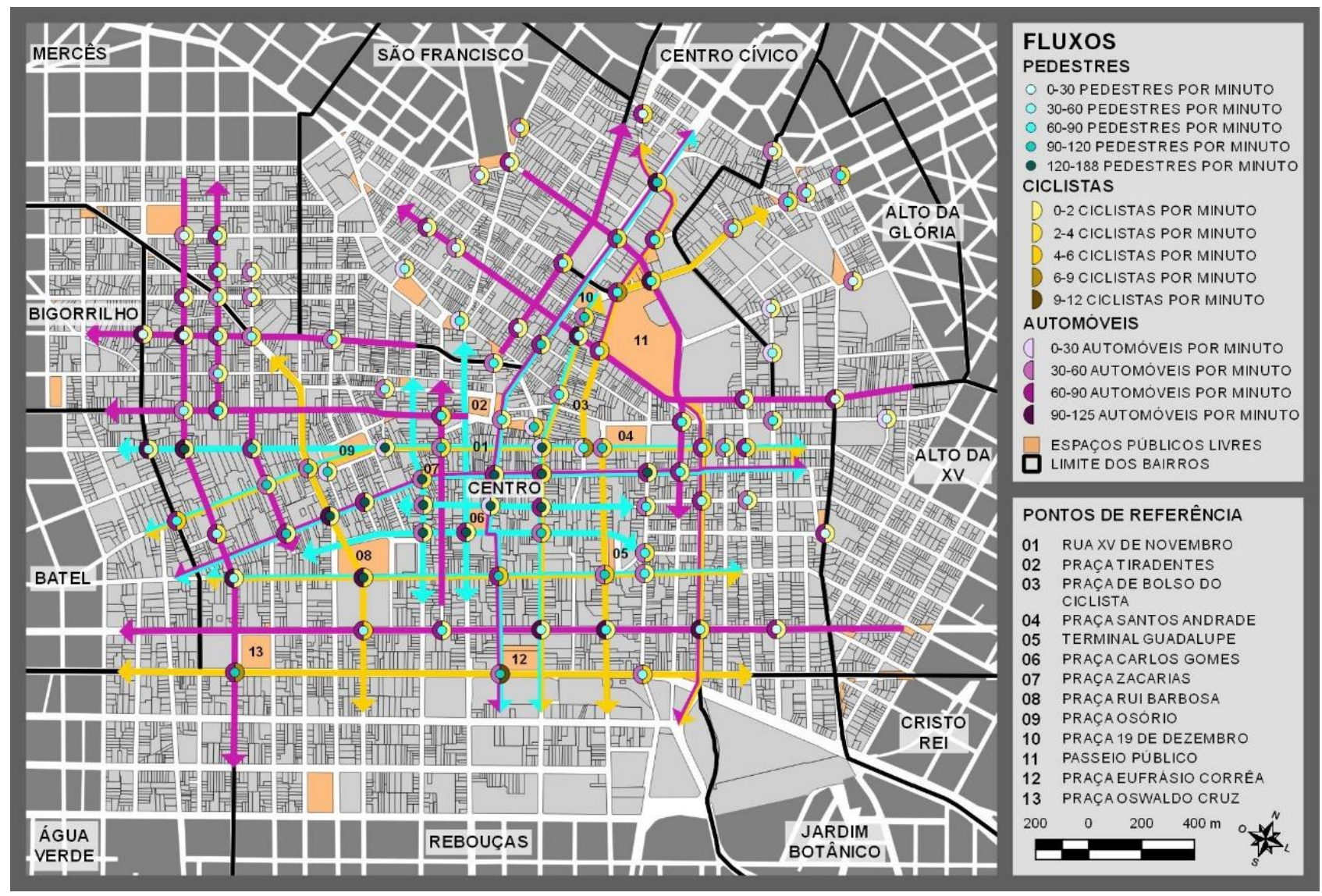

Fig. 07 Levantamento dos fluxos de deslocamento no bairro centro e seus arredores. Fonte: Elaboração própria, 2020

Através do levantamento pontual do fluxo de pedestres, de ciclistas e de veículos motorizados durante um minuto, em diversos pontos na área central (fig. 07), constatou-se que a existência de infraestrutura adequada para determinado modal está diretamente relacionada à preferência dos usuários do modal em utilizá-la. Como é o caso dos calçadões para pedestres próximos à Rua XV de Novembro, das ciclofaixas nas avenidas Sete de Setembro e João Gualberto e na Rua Mariano Torres, e das vias prioritárias para automóveis como a Rua Brigadeiro Franco e Presidente Carlos Cavalcanti.

Além disso, observa-se uma coexistência conflituosa entre a área com maior fluxo de pedestres e vias com alto fluxo de veículos. esse conflito também é nítido nas vias com faixas exclusivas para ônibus, que, em razão da escassez de infraestrutura cicloviária na área central, apresentam grande quantidade de ciclistas e usuários de micromodais compartilhados se deslocando.

\subsection{Síntese}

A partir dos levantamentos realizados, pode-se afirmar que o bairro Centro apresenta condições morfológicas, de usos e de fluxos essenciais para o desenvolvimento da mobilidade ativa, como por exemplo a presença de quadras curtas, mistura de usos e grande quantidade de pessoas se deslocando, seja a pé, de bicicleta, transporte público ou privado. 


\section{SÃO PAULO15 $\sim 17 \cdot$ LISBOA $25 \sim 26$ JUN 2020

Considerando tal cenário, pontuam-se os seguintes potenciais do bairro Centro que poderiam ser melhor explorados em planos e intervenções de mobilidade urbana na cidade: 1) eixos de uso misto circundados por áreas predominantemente residenciais; 2) núcleo central do bairro com quadras curtas, praças públicas importantes e grande variedade de comércio e serviço; 3) grande fluxo de usuários de modais ativos em área com infraestrutura de transporte coletivo consolidada; 4) ações de acalmamento de tráfego motorizado e implantação de infraestrutura adequada para modais ativos e compartilhados.

\section{Considerações finais}

Durante a elaboração deste artigo observou-se que, apesar de Curitiba possuir uma série de planos e políticas urbanas diretamente relacionadas à problemática da mobilidade ativa, seus detalhamentos e desdobramentos estão sendo insuficientes para promover condições adequadas para o desenvolvimento da mobilidade ativa no município, especialmente na área central.

Atribui-se essa realidade à desatualização e desintegração de tais instrumentos, que além de apresentarem e detalharem poucas ações concretas, contradizem-se em diversas questões, sendo a mais crítica a relativa à responsabilidade pela manutenção das calçadas.

Quanto ao bairro Centro, constata-se que seu potencial está sendo pouco explorado, visto que, como o levantamento expôs, ele apresenta caraterísticas determinantes para incentivar o uso dos modais ativos de transporte, como quadras curtas, diversidades de uso e alto fluxo de pessoas se deslocando.

Destacam-se, negativamente, ainda, as oportunidades que a municipalidade vem desperdiçando para se posicionar novamente como uma referência em planejamento urbano, através da condução de um desenvolvimento que priorize a escala humana e os modais de transporte ativos e coletivos. Primeiro, a dependência extrema em relação ao plano de 1966, que, apesar de muito importante, acaba prejudicando a análise plena do cenário futuro da cidade. Segundo, o desinteresse em ações que poderiam ser benéficas para a cidade, como as intervenções de desenho urbano na Área Calma do centro da cidade e o apoio aos recentes sistemas de compartilhamento de bicicletas e patinetes. Terceiro, a pouca efetividade dos planos estratégicos de mobilidade devido à falta de integração e correspondência entre eles. Por último, a insistência em desenvolver uma nova proposta para um Plano de Estrutura Cicloviária, sem antes atualizar o Plano de Mobilidade Urbana e Transportes do município em relação às demandas atuais e futuras da cidade.

\section{Referências Bibliográficas}

\subsubsection{Obra completa}

ANDRADE, V. e LINKE, C. C. (Orgs.) (2017). Cidades de Pedestres: A caminhabilidade no Brasil e no Mundo. Rio de Janeiro: Babilonia Cultura Editorial.

BELOTTO, J. C. A. (2014). Por que os ciclistas curitibanos escolheram as canaletas? En BELOTTO, J. C. A. et al. (Orgs.). A cidade em equilíbrio: Contribuições teóricas ao 3ํ Fórum Mundial da Bicicleta - Curitiba 2014 (155-157). Curitiba: Proec/UFPR.

BRASIL. (2012). Lei Federal no 12.587, de 03 de janeiro de 2012. Institui as diretrizes da Política Nacional de Mobilidade Urbana. Presidência da República, Casa Civil, Subchefia para assuntos jurídicos, Brasília, Brasil.

COHEN, J. L. O futuro da arquitetura desde 1889: Uma história mundial (2013). São Paulo: Cosac Naify. 


\section{SÃOPAULO15 $17 \cdot$ LISBOA $25 \sim 26$ JUN 2020}

CURITIBA. (2006). Decreto Municipal № 1.066, de 25 de setembro de 2006. Regulamenta a Lei N.․․ 11.596/2005 e estabelece critérios para a construção ou reconstrução de passeios nos locais que especifica. Prefeitura Municipal de Curitiba, Curitiba, PR.

CURITIBA. (2004). Lei Municipal № 11.095, de 08 de junho de 2004. Dispõe sobre as normas que regulam a aprovação de projetos, o licenciamento de obras e atividades, a execução, manutenção e conservação de obras no Município, e dá outras providências. Prefeitura Municipal de Curitiba, Curitiba, PR.

CURITIBA. (2005). Lei Municipal № 11.596, de 24 de novembro de 2005. Dispõe sobre a construção, reconstrução e conservação de calçadas, vedação de terrenos, tapumes e stands de vendas, cria o programa caminhos da cidade - Readequação de calçadas de Curitiba e o Fundo de Recuperação de Calçadas - FUNRECAL, revoga a Lei № 8.365 de 22 de dezembro de 1993, e dá outras providências. Prefeitura Municipal de Curitiba, Curitiba, PR.

CURITIBA. (2015). Lei Municipal № 14.771, de 17 de dezembro de 2015. Dispõe sobre a revisão do Plano Diretor de Curitiba de acordo com o disposto no art. 40, § 3o, do Estatuto da Cidade, para orientação e controle do desenvolvimento integrado do Município. Prefeitura Municipal de Curitiba, Curitiba, PR.

GEHL, J. (2015). Cidade para pessoas. São Paulo: Perspectiva.

IRAZÁBAL, C. (2018). Desenho Urbano, Planejamento e Políticas de Desenvolvimento em Curitiba. En DEL RIO, V.; SIEMBIEDA, W. (Orgs). Desenho Urbano contemporâneo no Brasil (179-197). Rio de Janeiro: LTC.

JACOBS, J. B. (2011). Morte e vida de grandes cidades. São Paulo: WMF Martins Fontes.

JANKOWSKI, B. M. K. (2019). Planejamento urbano como promotor da mobilidade ativa. 151f. Trabalho Final de Graduação (Bacharelado em Arquitetura e Urbanismo) - Setor de Tecnologia, Universidade Federal do Paraná.

LEITE, C. e AWAD, J. di. C. M. (2012). Cidades sustentáveis, cidades inteligentes: desenvolvimento sustentável num planeta urbano. Porto Alegre: Bookman.

PATRICIO, L. C. B. e MEDEIROS, R. M. (2015). Curitiba: Avanços históricos e políticas questionáveis. En SOARES, A. G. et al. A bicicleta no Brasil: 2015 (50-55). São Paulo: D. Guth.

SPECK, J. (2017). Cidade Caminhável. São Paulo: Perspectiva.

VARGAS, J. C. e NETTO, V. M. (2017). Condições urbanas da caminhabilidade. En: ANDRADE, V. e LINKE, C. C. (Orgs.). Cidades de Pedestres: A caminhabilidade no Brasil e no Mundo (190-203). Rio de Janeiro: Babilonia Cultura Editorial.

\subsubsection{Fontes eletrônicas}

BRASIL. (2017). Ministério das Cidades; Secretaria Nacional de Mobilidade Urbana; WRI Brasil. Caderno técnico para projetos de mobilidade urbana: Transporte ativo. Brasília. Disponível em: https://wribrasil.org.br/sites/default/files/CadernosTecnicos_TransporteAtivo.pdf (consulta: 06/03/2020).

CURITIBA. (2008). Plano Municipal de Mobilidade Urbana e Transporte Integrado: PlanMob Curitiba Proposta final. Curitiba. Disponível em: https://ippuc.org.br/visualizar.php?doc=http://admsite2013.ippuc.org.br/arquivos/documentos/D312/D312_005 _BR.pdf (consulta: 06/03/2020). 


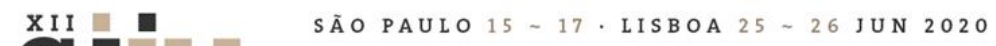

Seminário Internacional de Investigação em Urbanismo

Seminario Internacional de Investigación en Urbanismo

IPPUC. (2013). Plano Estratégico Cicloviário de Curitiba. Curitiba. Disponível em: https://ippuc.org.br/visualizar.php?doc=http://admsite2013.ippuc.org.br/arquivos/documentos/D313/D313_001 _BR.pdf (consulta: 06/03/2020).

IPPUC. (2014). Plano Estratégico de Calçadas. Curitiba. Disponível em: https://ippuc.org.br/visualizar.php?doc=http://admsite2013.ippuc.org.br/arquivos/documentos/D313/D313_004 _BR.pdf (consulta: 06/03/2020).

ONU. (2017). Glossary of the Habitat III: Preparatory Process and the Conference. Quito. Disponível em: http://habitat3.org/wp-content/uploads/Habitat-III-Glossary.pdf (consulta:06/03/2020). 